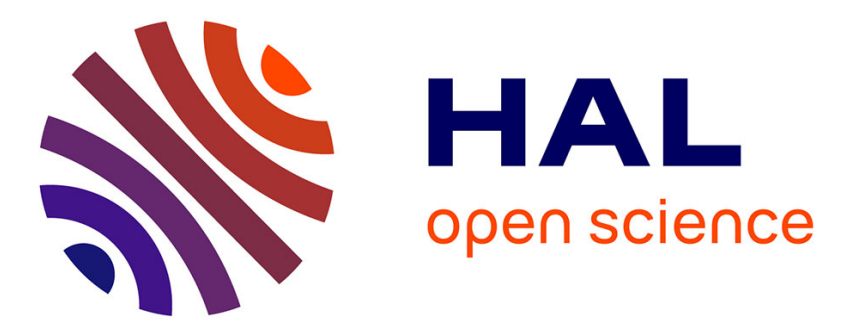

\title{
Characterization of transport of titanium neutral atoms sputtered in Ar and Ar/N 2 HIPIMS discharges
}

\author{
A El Farsy, J. Ledig, M Desecures, J. Bougdira, L. de Poucques
}

\section{To cite this version:}

A El Farsy, J. Ledig, M Desecures, J. Bougdira, L. de Poucques. Characterization of transport of titanium neutral atoms sputtered in Ar and Ar/N 2 HIPIMS discharges. Plasma Sources Science and Technology, 2019, 28 (3), pp.035005. 10.1088/1361-6595/ab022b . hal-02319596

\section{HAL Id: hal-02319596 https://hal.science/hal-02319596}

Submitted on 18 Oct 2019

HAL is a multi-disciplinary open access archive for the deposit and dissemination of scientific research documents, whether they are published or not. The documents may come from teaching and research institutions in France or abroad, or from public or private research centers.
L'archive ouverte pluridisciplinaire HAL, est destinée au dépôt et à la diffusion de documents scientifiques de niveau recherche, publiés ou non, émanant des établissements d'enseignement et de recherche français ou étrangers, des laboratoires publics ou privés. 


\title{
Characterization of transport of Titanium neutral atoms sputtered in Ar and Ar/ $\mathbf{N}_{2}$ HIPIMS discharges
}

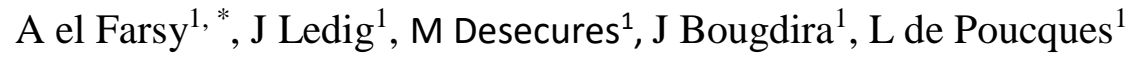 \\ ${ }^{1}$ Institut Jean Lamour UMR 7198, CNRS - Université de Lorraine, Campus ARTEM, F- \\ 54011 Nancy, France. \\ * Corresponding author: abderzak.el-farsy@univ-lorraine.fr
}

\begin{abstract}
We report in this work the investigation of the transport behavior of Ti neutral atoms sputtered in reactive high power impulse magnetron sputtering (R-HiPIMS) device used for TiN coating deposition. The time resolved tunable diode laser induced fluorescence (TR-TDLIF), previously developed to study the transport of tungsten atoms, was improved to measure Ti neutral atoms velocity distribution functions. We find that the TR-TDLIF signal has to be fitted using three Gaussian distributions, corresponding to the energetic (EN), thermalized (TH) and quasi-thermalized (QTH: $\mathrm{TH}$ atoms with non-zero mean velocity) atoms populations. Then, the ability to distinguish populations of atoms and to determine their corresponding deposited flux and energy may be of great interest to control film properties as desired for targeted applications. From the fitting, the vapor transport parameters (flux and energy) are calculated and studied as function of distance from the target, pressure and percentage of nitrogen in $\mathrm{Ar} / \mathrm{N}_{2}$ gas mixture. The study focuses on the effect of added nitrogen on the transport of sputtered atoms.
\end{abstract}

Keywords: time resolved tunable diode laser induced fluorescence, reactive magnetron sputtering, high power impulse magnetron sputtering (HiPIMS), atoms velocity distribution function, transport of sputtered atoms, titanium, nitrogen

\section{Introduction}

Since the 1970s, magnetron sputtering (MS) process has been developed for the growth of thin films by physical vapor deposition (PVD) [1]. The developments of conventional reactive direct current (R-dcMS) and radiofrequency (R-rfMS) magnetron sputtering methods allow the deposition of a wide range of thin films of materials such as metals, oxides, nitrides, ceramics, etc. [2]. Consequently, MS is a widely used deposition technology in many industrial applications. 
In conventional magnetron sputtering discharges, sputtered species are mainly emitted by the cathode as neutral particles and ions of the sputtered material do not contribute significantly to the deposition process. Ionized Physical Vapor Deposition (IPVD) reactors have then been developed since the 1990s to improve the quality of deposited films in terms of mechanical properties (higher density, reduced porosity, better resistance to corrosion) and of conformity for deposition on complex substrate geometry [3-8]. The main goal of IPVD is to ionize a fraction of neutral species sputtered from the magnetron target in order to transfer potential energy to ions, and to collimate and control the obtained ion particle fluxes by applying a negative bias voltage to the substrate. IPVD reactors consist of a magnetron discharge assisted by an additional plasma source, located in the area between the substrate and the magnetron cathode, which ionizes the sputtered vapor flowing from the magnetron. Reactors using helicon [9], electron cyclotron resonance (ECR) coupled discharge [10] or microwave surface wave plasma [11] have been studied but most of the IPVD reactors used radio-frequency coils (RF-IPVD) to create the additional ionization [4, 5, 12, 13]. Some difficulties, however, have to be tackled in RF-IPVD processes. Indeed, the necessary modifications of the reactor chamber design and the fact that the internal antenna immersed in the reactor could pollute the deposition process [13-15], present potential inconveniences for some applications. Moreover, the ionization degree may be too low for specific applications such as the filling of trenches, as well as for new functional coatings demands.

Therefore, high power impulse magnetron sputtering process (HiPIMS) has been developed [16] and intensively studied since the end of the 1990s [17-22], and reactive HiPIMS (R-HiPIMS) has emerged since 2002 [23] for the adhesion enhancement of $\mathrm{CrN}$ hard coatings on steel [24]. In HiPIMS process, the high power $\left(\mathrm{a}\right.$ few $\left.\mathrm{kW} . \mathrm{cm}^{-2}\right)$ is turned on during short pulses (tens of $\mu \mathrm{s}$ ) in order to avoid the cathode overheating and arc formation. The plasma density is usually between $10^{12}$ and $10^{13} \mathrm{~cm}^{-3}[16,25]$ and the ionization degree of the sputtered particles is greater than $50 \%$ [25]. The main advantage of HiPIMS and RHiPIMS technologies is the absence of an additional ionization antenna in the reactor chamber, i.e. an industrial reactor can be upgraded to a HiPIMS one only by changing the power supply. Furthermore, in R-HiPIMS process, the poisoning of the target and the plasma composition are not only induced by the partial pressure of the reactive gas and the power as in dcMS, since discharge duration and pulse repetition rates are also key parameters for the balance between sputtering and sticking of reactive species [26].

For a better understanding of both non-reactive and reactive HiPIMS discharges, the development of time and/or space resolved suitable diagnostics allowing the study of neutral and ionic particle fluxes (densities and energies) between the target and the substrate is required. The objectives are to control and optimize the deposition process. Ion energy distribution functions (IEDFs) of ions created from the ionization of sputtered particles and the gas are often measured by time-average and/or time-resolved mass spectrometry [27-32]. Moreover, some measurements of charged and neutral (since a significant fraction of neutral species remains and may influence thin film deposition properties) particles were carried out by time-resolved and space-resolved optical emission spectroscopy [33, 34], laser induced 
fluorescence with a YAG:Nd laser [35] or resonant optical absorption spectroscopy [36]. Recently, the velocity distribution of sputtered titanium in the target vicinity of a HiPIMS discharge, and the relaxation from Thompson distribution to Maxwell one, were reported by Held et al. [37].

In previous papers [38, 39], we presented new measurements of atoms velocity distribution functions (AVDFs) of the metastable state of neutral tungsten (W) obtained by means of time resolved tunable diode laser induced fluorescence (TR-TDLIF) in non-reactive (pure Ar gas) HiPIMS discharges. The present work is focused on R-HiPIMS process study used for titanium nitride (TiN) thin film deposition. TiN was chosen for its good mechanical and optical properties, excellent chemical resistance and good biocompatibility. However, the scope of this paper is not devoted to film properties. Thin films were deposited in order to compare and corroborate TR-TDLIF measurements and deposition rate (estimated by scanning electron microscopy). The main goal is to develop TR-TDLIF on the ground state of neutral $\mathrm{Ti}$ atoms. Indeed, this method performed on $\mathrm{W}$ has been drastically improved to be able to measure the very low intensity of the Ti fluorescence signal, especially when $\mathrm{N}_{2}$ is added in the $\mathrm{Ar} / \mathrm{N}_{2}$ gas mixture (owing to the high decrease of number of $\mathrm{Ti}$ atoms sputtered from the poisoned target). Furthermore, the appearance, reduction or vanishing of hysteresis [see 26 and therein] is not discussed here because the main objective is to present reliable TRTDLIF measurements. We report the evolution of Ti AVDFs showing the different stages of the atoms transport and highlighting an intermediate regime between ballistic and diffusive ones (named quasi-diffusive or quasi-thermalized). Spatio-temporal evolutions of absolute densities, fluxes and energies are characterized by varying the percentage of $\mathrm{N}_{2}$ in the gas mixture. This study may be a significant step in the ability to control film properties.

\section{Experimental setup}

As presented in a previous work [40] our reactor was used to develop the time resolved tunable diode laser induced fluorescence measurements. The balanced magnetron cathode is fitted with a water cooled Titanium target of $5 \mathrm{~cm}$ in diameter, $3 \mathrm{~mm}$ in thickness and $99.99 \%$ of purity. Prior to discharge process, the vacuum reaches a pressure lower than $2 \times 10^{-4} \mathrm{~Pa}$. $\mathrm{Ar}$ and $\mathrm{N}_{2}$ gases were added into the chamber with various $\mathrm{N}_{2} / \mathrm{Ar}$ flow rate ratio $(0-10 \%)$ while the total flow rate was fixed at $18 \mathrm{sccm}$. The TR-TDLIF measurements were carried out at fixed discharge power $\left(350 \mathrm{~W} . \mathrm{cm}^{-2}\right)$ and discharge time $\left(\mathrm{T}_{\mathrm{d}}=10 \mu \mathrm{s}\right.$ and $\mathrm{f}=1 \mathrm{kHz}$ : corresponding to a duty cycle of $1 \%$ ). These parameters have an important role in the process. Indeed, we have not studied the repetition frequency and the pulse duration, but Magnus et al. [41] reported that the repetition frequency has an effect on the transition from metallic to compound mode. In addition, Ferrec et al. [28] reported that at small average HiPIMS power $\left(7 \mathrm{~W} \mathrm{~cm}^{-2}\right)$ a long discharge time produces more argon ions whereas a short one generates more metallic ions whereas Konstantinidis et al. [42] suggested the reverse at higher power due to the sputtering wind (inducing a local decrease of the argon density, consequently Ar ions density, due to the intense target sputtering gas rarefaction). In fact, these parameters, especially the short $T_{d}$ and the limited HiPIMS power, were mainly chosen to separate the discharge from the post-discharge and to perform TR-TDLIF measurement close to the target surface (at $\mathrm{z}=1.3 \mathrm{~cm}$ since the sputtered $\mathrm{Ti}$ get thermalized quickly by 
collisions with the background gas) and study the transport of metallic vapor with limited disturbances linked to the plasma (strong optical emission at high power discharge and $\mathrm{Ti}$ atoms production during a long time when using a long $\mathrm{T}_{\mathrm{d}}$ ).

Diode laser (DL) used to excite the neutral sputtered atoms, Toptica Phototonics DL 100 (20 $\mathrm{mW}$ ), provide a $14 \mathrm{pm}$ wavelength range $\left(\lambda_{\text {laser }}\right)$ without mode hop and centered at $\lambda_{0}=398.170$ $\mathrm{nm}$ (the same transition used by Sushkov et al. [43]), which is suitable to probe wide range of sputtered atoms velocities. The DL has a high spectral resolution $(0.005 \mathrm{pm})$ compared to that of an OPO laser $(\sim 2 \mathrm{pm})$ or a dye Nd:YAG laser $(\sim 0.5 \mathrm{pm}) . \lambda_{0}$ corresponds to the neutral $\mathrm{Ti}$ resonance transition from the ground state level $3 \mathrm{~d}^{2} 4 \mathrm{~s}^{2}-\left(\mathrm{a}^{3} \mathrm{~F}_{2}\right)$ to the short lifetime radiative excited level $3 d^{2}\left({ }^{3} \mathrm{~F}\right) 4 \mathrm{~s} 4 \mathrm{p}\left({ }^{1} \mathrm{P}^{\circ}\right)-\left(\mathrm{y}^{3} \mathrm{~F}_{2}\right)$. The fluorescence signal $\left(\lambda_{\mathrm{LIF}}\right)$ also emitted at $\lambda_{\text {laser. }}$. The detailed description of the optical and electrical arrangements can be found in a previous work [38]. The HiPIMS unit was set to deliver 180 pulses during the 14-pm wavelength scan. The wavelength variation during one HiPIMS pulse period $(1 \mathrm{~ms})$ is assumed to be negligible since it generates a Doppler shift error of $0.077 \mathrm{pm}$. This corresponds to a $60 \mathrm{~m} / \mathrm{s}$ error on velocity while the measured velocities are in the order of $\mathrm{km} / \mathrm{s}$. The laser beam probes the axial (perpendicular to the target surface) velocity component of sputtered atoms $\left(\overrightarrow{v_{z}}\right.$, see figure 1 (a)). The magnetron target was moved in $\mathrm{z}$ direction $(\mathrm{z}=0 \mathrm{~cm}$ corresponding to the target surface) to perform measurements at various "target/probed volume" distances. All measurements were carried out between $\mathrm{z}=1.3 \mathrm{~cm}$ and $8 \mathrm{~cm}$ above the racetrack and $\mathrm{R}_{0}=1.3$ $\mathrm{cm}$ from the center of the target. At $\mathrm{z}=1.3 \mathrm{~cm}$, the $\mathrm{B}$ value is lower than $20 \mathrm{G}$ and quasihomogeneous.

(a)

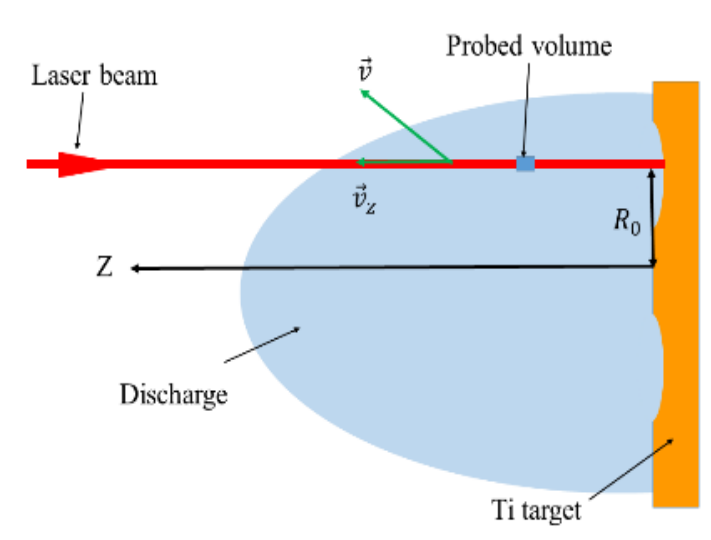

(b)

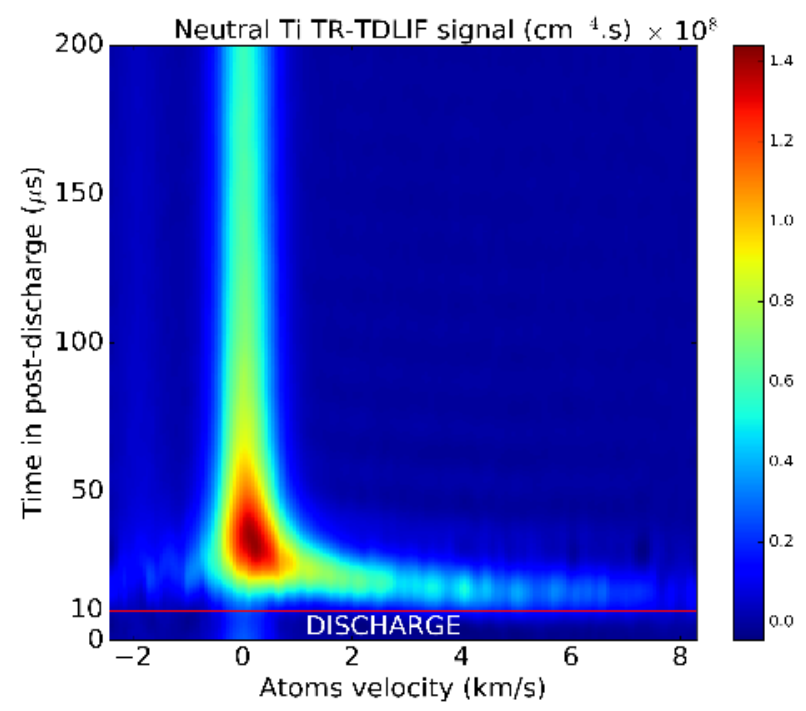

Figure 1: (a) Experimental set-up for TR-TDLIF measurements of sputtered Ti atoms in the axial direction (perpendicular to the target surface). (b) Typical Ti neutral sputtered atoms distribution measured at $z=1.3 \mathrm{~cm}, R_{0}=1.3 \mathrm{~cm}, p=0.7 \mathrm{~Pa}, P=350 \mathrm{~W} . \mathrm{cm}^{-2}$, and with pure Argon gas. 
In order to obtain absolute measurements, time resolved tunable diode laser absorption spectroscopy (TR-TDLAS) was used to calibrate the TR-TDLIF signal. The absorption process has to be as homogeneous as possible along the laser beam path (absorption length) during TR-TDLAS measurement. Thus, the calibration was performed in conditions where the sputtered atoms have isotropic distribution (thermalized vapor), i.e. far away from target $(\mathrm{z}=8 \mathrm{~cm})$, at relatively high pressure $(\mathrm{p}=2.7 \mathrm{~Pa})$ and at the end of the post-discharge (700$900 \mu \mathrm{s})$. The contributions of the Stark and pressure broadenings were neglected due to the low electron density/electric field in the post-discharge and the very low working gas pressure (between 0.7 and $2.7 \mathrm{~Pa}$ ). Furthermore, Zeeman effect does not contribute to line broadening in our conditions. Only Doppler broadening and shift are, then, taking into account. Therefore, to convert the laser wavelength scale $\left(\Delta \lambda_{\text {laser }}=\lambda_{\text {laser }}-\lambda_{0}\right.$ was determined by means of a Fabry-Pérot interferometer) into the velocity scale, the classical Doppler's relation $\left(v=c \cdot \Delta \lambda_{\text {laser }} / \lambda_{0}\right)$ was applied. Figure 1 (b) shows a typical 2D-image of the AVDF (atoms velocity $v_{z}, t$ ) of the Ti neutral atoms velocity distribution functions measured with TRTDLIF in a HiPIMS post-discharge.

\section{Results and discussions}

\section{III-1. Quasi-thermalized atoms with non-zero mean velocity}

Time resolved tunable diode laser induced fluorescence measurements give access to the atoms velocity distribution functions (AVDF). The latter have to be theoretically fitted to distinguish the various atoms populations and to calculate their related properties: density, flux, energy, etc.

In a previous work, Desecures et al. [39] studied the transport of tungsten sputtered atoms in HiPIMS discharge and showed that two populations coexist: the anisotropic and thermalized atoms. Then, the TR-TDLIF signal has been fitted using two Gaussian distributions. However, after carrying an extensive analysis of the parameters evolutions in the postdischarge, we have concluded that the anisotropic population contains itself two populations: the energetic atoms and quasi-thermalized atoms with non-zero mean velocity. The different stages of atoms transport were then accessible. When Ti atoms collide with Ar atoms, they lose in average $50 \%$ of their initial energy, contrary to $\mathrm{W}$ atoms which lose only $30 \%$ (see table 1). In fact, a sputtered Ti atom with energy of $4 \mathrm{eV}$ (average energy of Ti EN atoms ejected from the target is, depending on the cathode voltage, usually between 3 and $5 \mathrm{eV}$ ) becomes thermalized after 7-8 collisions but the thermalization of a sputtered $\mathrm{W}$ atom with same energy needs 11-12 collisions. 
Table 1: Average fraction of energy lost $\left(\mathbf{1}-\boldsymbol{E}_{\boldsymbol{f}} / \boldsymbol{E}_{\boldsymbol{i}}\right)$ of the sputtered atoms after one collision with the buffer gas $\left(E_{i}=\right.$ initial energy; $E_{f}=$ final energy).

\begin{tabular}{|c|c|c|c|}
\hline Gas & Ar (40 amu) & $\mathrm{N}_{2}(28 \mathrm{amu})$ & $\mathrm{N}(14 \mathrm{amu})$ \\
\hline $\mathrm{W}(183 \mathrm{amu})$ & 0.30 & 0.24 & 0.14 \\
\hline $\mathrm{Ti}(48 \mathrm{amu})$ & 0.50 & 0.47 & 0.35 \\
\hline
\end{tabular}
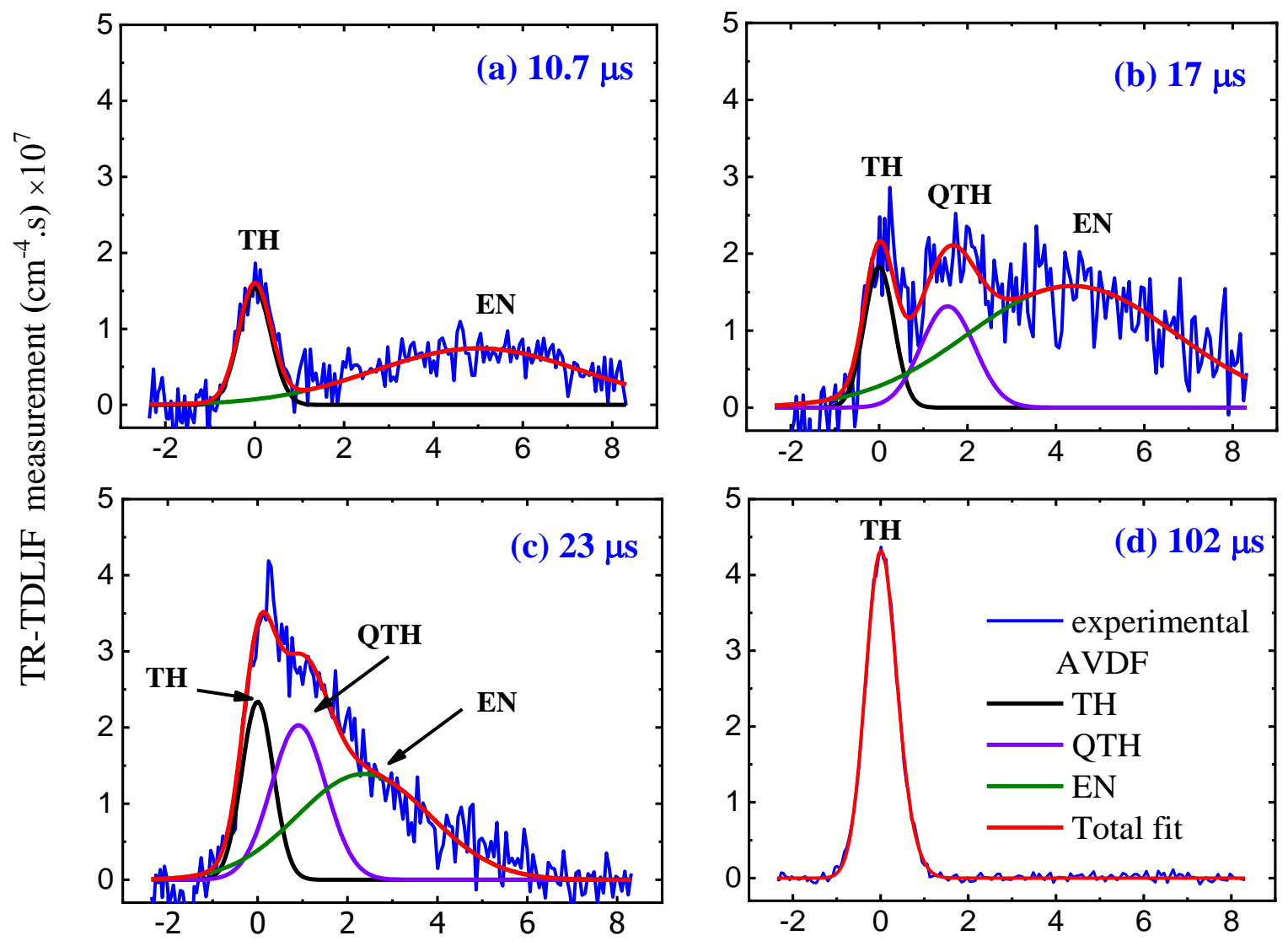

Atoms velocity $\left(\mathrm{km} . \mathrm{s}^{-1}\right)$

Figure 2 : Neutral Titanium atoms velocity distribution functions measured with TR-TDLIF technique at $p=2.7 \mathrm{~Pa}, z=2 \mathrm{~cm}, P=350 \mathrm{~W} . \mathrm{cm}^{-2}$ and pure Ar, for various times in the post-discharge : (a) 10.7 $\mu s$, (b) $17 \mu s,(c) 23 \mu s$ and (d) $102 \mu s$.

It is important to point out that $\mathrm{W}$ atoms keep their momentum (direction and velocity) longer due to their large mass compared with the buffer gas atoms, while Ti atoms evolve more rapidly towards an isotropic distribution. To study the transport of Ti neutral sputtered atoms, velocity distribution functions for different times in post-discharge are given in figure 2. Figure 2(a) represents the AVDF at the beginning of the post-discharge $(t=10.7 \mu \mathrm{s})$ and clearly shows two populations (EN and $\mathrm{TH}$ ). Indeed, one can observe that the experiment curve is well fitted with two Gaussians. The population centered at $\mathrm{v}_{\mathrm{z}}=0$ corresponds to the residual thermalized neutral atoms $(\mathrm{TH})$ measured in the probed volume at the end of the 
post-discharge (they cannot be new thermalized atoms produced during $\mathrm{t}=10.7 \mu$ s from the beginning of the short discharge time $-\mathrm{T}_{\mathrm{d}}=10 \mu \mathrm{s}$ ). The second population centered at $\mathrm{v}_{\mathrm{z}}=4.5$ $\mathrm{km} . \mathrm{s}^{-1}$ represents the new high velocity sputtered atoms created during the discharge (EN distribution function). Figures 2(b) and 2(c) highlight unexpected profiles at intermediate times $(\mathrm{t}=17$ and $23 \mu \mathrm{s})$. They clearly show a third peak at $\mathrm{v}_{\mathrm{z}}=1.5 \mathrm{~km} \cdot \mathrm{s}^{-1}$ for $\mathrm{t}=17 \mu \mathrm{s}$ and 1 $\mathrm{km} . \mathrm{s}^{-1}$ for $\mathrm{t}=23 \mu \mathrm{s}$. Since the fit with two Gaussians, we have assumed that AVDF is the sum of three populations. This third population is an intermediate population between EN (ballistic transport) and $\mathrm{TH}$ (diffusive transport) ones. Its average energy is $\sim 0.5 \mathrm{eV}$ at $\mathrm{t}=17 \mu \mathrm{s}, \sim 0.2 \mathrm{eV}$ at $\mathrm{t}=23 \mu \mathrm{s}$, and decreases down to the thermal energy of $\mathrm{TH}$ atoms $(\sim 0.05 \mathrm{eV})$ for later times in the post-discharge. That is the reason this population is named "QTH: Quasi Thermalized Atoms", for TH atoms with a non-zero mean velocity. It is produced by collisions of EN atoms with the buffer gas and a few collisions are missing to reach a complete isotropic AVDF (mean velocity=zero). In figure 2(d) one can notice that only one Gaussian (TH population) is needed to well fit the experimental TR-TDLIF signal at $\mathrm{t}=102 \mu$ s because EN atoms have already crossed the probed volume $(\mathrm{z}=2 \mathrm{~cm})$ at this late time in the postdischarge.

\section{III-2. Time evolution of sputtered atoms properties in the post- discharge}

From the fit of the TR-TDLIF measurements with three Gaussians, time evolutions of TH, QTH and EN populations are determined. The integrals over $\mathrm{v}_{\mathrm{z}}\left(\mathrm{v}_{\mathrm{z}}>0\right.$ in order to take into account only atoms going towards the probed volume or substrate) of the AVDF for each TH, EN and QTH population, at any time in the post-discharge, define the densities of neutral atoms $[\mathrm{Ti}]_{\mathrm{TH}}(\mathrm{t})$, $[\mathrm{Ti}]_{\mathrm{EN}}(\mathrm{t})$ and $[\mathrm{Ti}]_{\mathrm{QTH}}(\mathrm{t})$ :

$$
\begin{array}{r}
{[\mathrm{Ti}]_{\mathrm{i}}(\mathrm{t})=\int_{0}^{\infty} \operatorname{AVDF}_{\mathrm{i}}\left(\mathrm{v}_{\mathrm{z}}, \mathrm{t}\right) \mathrm{dv}_{\mathrm{z}}} \\
\text { where } \mathrm{i}=\mathrm{TH}, \mathrm{EN} \text { or QTH. }
\end{array}
$$

Similarly, the integrals of AVDF $\times \mathrm{v}_{\mathrm{z}}$ give the fluxes directed (deposited fluxes) towards the substrate $\Phi_{\mathrm{TH}}(\mathrm{t}), \Phi_{\mathrm{EN}}(\mathrm{t})$ and $\Phi_{\mathrm{QTH}}(\mathrm{t})$ :

$$
\Phi_{\mathrm{i}}(\mathrm{t})=\int_{0}^{\infty} \mathrm{v}_{\mathrm{z}} \operatorname{AVDF}_{\mathrm{i}}\left(\mathrm{v}_{\mathrm{z}}, \mathrm{t}\right) d \mathrm{v}_{\mathrm{z}}
$$

The integrals of $A V D F \times v_{z}^{2} \times m / 2$ give deposited energies $E_{T H}(t), E_{E N}(t)$ and $E_{Q T H}(t)$ :

$$
\mathrm{E}_{\mathrm{i}}(\mathrm{t})=\frac{1}{2} \mathrm{~m} \int_{0}^{\infty} \mathrm{v}_{\mathrm{z}}^{2} \operatorname{AVDF}_{\mathrm{i}}\left(\mathrm{v}_{\mathrm{z}}, \mathrm{t}\right) d \mathrm{v}_{\mathrm{z}}
$$

The average energy of each population atoms is defined as:

$$
E_{A v-i}(t)=\frac{E_{i}(t)}{\int_{0}^{\infty} A V D F_{i}\left(v_{z}, t\right) d v_{z}}
$$



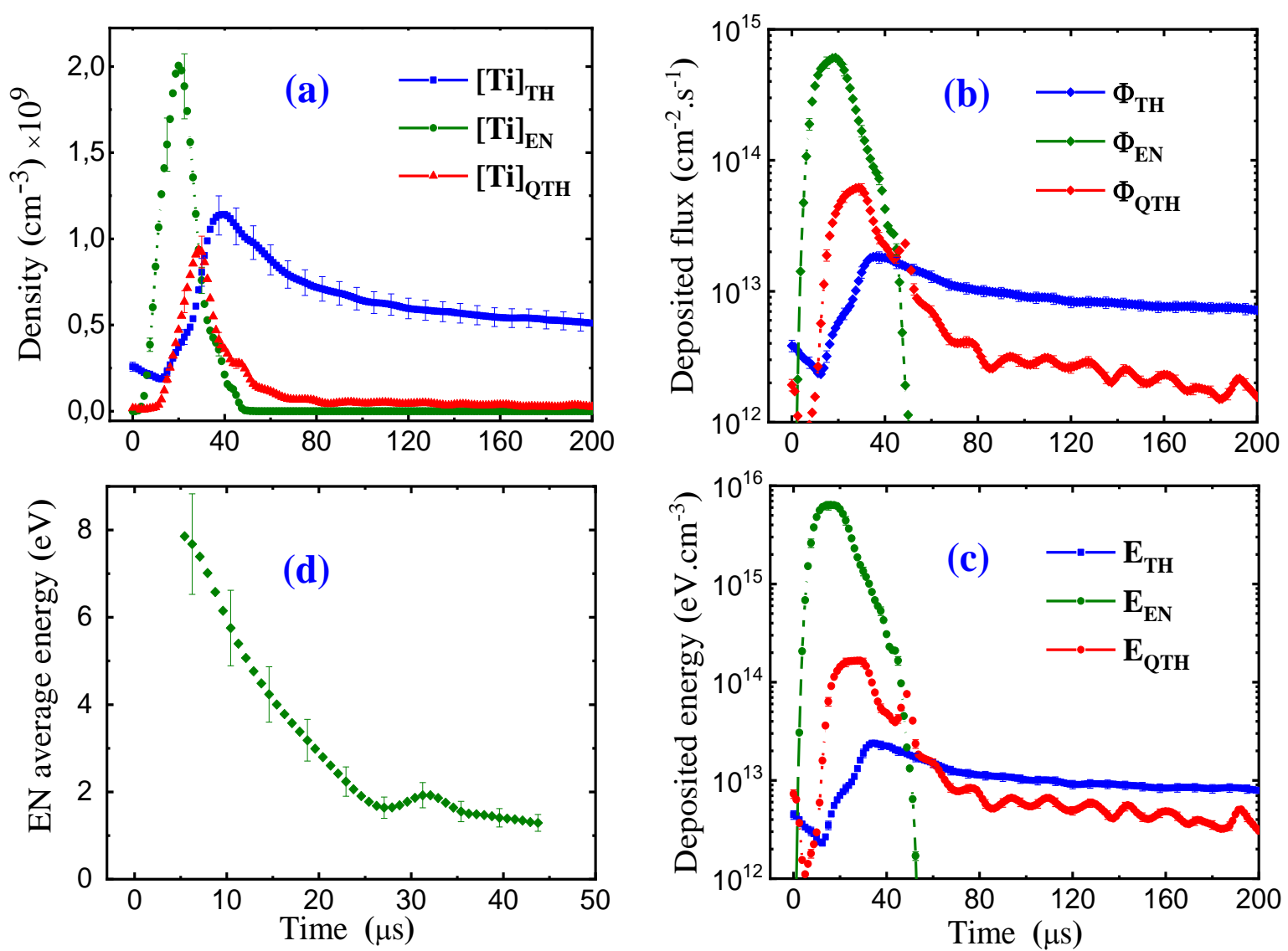

Figure 3: Temporal variations of density (a), deposited flux (b) and deposited energy (c) of thermalized (TH), energetic (EN) and quasi-thermalized (QTH) atoms populations. Time evolution of EN atoms average energy $(d)$. At $p=2.7 \mathrm{~Pa}, z=1.3 \mathrm{~cm}, P=350 \mathrm{~W} . \mathrm{cm}^{-2}$ and pure Ar.

Figure 3(a) shows the time evolutions of titanium ground state atoms densities at a distance close to the target $\left(\mathrm{z}=1.3 \mathrm{~cm}\right.$ ), at $2.7 \mathrm{~Pa}$ (pure Ar) and a HiPIMS power of $350 \mathrm{~W} . \mathrm{cm}^{-2}$. As shown in figure $3(\mathrm{~d})$, the $\mathrm{EN}$ average energy $\left(\mathrm{E}_{\mathrm{av}-\mathrm{EN}}\right)$ decreases in post-discharge from $8 \mathrm{eV}$ to $1.5 \mathrm{eV}$. This high energy permits EN atoms to cross the probed volume in the first $50 \mu \mathrm{s}$ (ballistic transport). As TH atoms have a much lower average energy $\left(\mathrm{E}_{\mathrm{av}-\mathrm{TH}} \sim 0.05 \mathrm{eV}\right)$ and a diffusive regime of transport, they can be measured in the probed volume during the whole post-discharge $(1 \mathrm{~ms})$. One can observe two slopes during the increase of [Ti $]_{\mathrm{TH}}(\mathrm{t})$. The first one occurs during the $[\mathrm{Ti}]_{\mathrm{QTH}}(\mathrm{t})$ increase and the greater one during the $[\mathrm{Ti}]_{\mathrm{QTH}}(\mathrm{t})$ drop. The first slope seems to correspond to source term of TH atoms (by collisions of QTH atoms with the buffer gas) with relatively low [Ti $]_{\mathrm{QTH}}$ (and $\mathrm{E}_{\mathrm{av}-\mathrm{QTH}}$ between 0.5 and $0.2 \mathrm{eV}$ ) and the second one to higher source term with higher [Ti $]_{\mathrm{QTH}}$ (and $\mathrm{E}_{\text {аv-Qтн }}$ between 0.2 and $0.05 \mathrm{eV}$ ). The drop of $[\mathrm{Ti}]_{\mathrm{QTH}}(\mathrm{t})$ can be the result of the losses of QTH atoms, close to the target, which are no more compensated by the term source of [Ti $]_{\mathrm{QTH}}$ (collisions of EN atoms with the buffer gas). The time evolutions of the corresponding deposited flux and deposited energy are plotted in figures 3(b) and 3(c). Unlike densities of the three populations, the deposited flux maximum of EN atoms is at least ten times higher than the QTH and TH ones because the mean velocity of EN population is much higher than the QTH and TH ones $\left.\left(\langle\mathrm{v}\rangle_{\mathrm{EN}}\right\rangle\right\rangle\langle\mathrm{v}\rangle_{\mathrm{QTH}} \geq$ $\left.\langle\mathrm{v}\rangle_{\mathrm{TH}}\right)$. It is then more suitable to analyze the fluxes rather than densities to study the atoms transport. 
From curves of figures 3(b) and 3(c), the energy $\left(E_{i}^{i n t}\right)$ integrated over a HiPIMS period are given by the following integral:

$$
E_{\mathrm{i}}^{\mathrm{int}}=\int_{0}^{1 \mathrm{~ms}} \mathrm{E}_{\mathrm{i}}(\mathrm{t}) \mathrm{dt}
$$

$$
\text { where } \mathrm{i}=\mathrm{TH}, \mathrm{EN} \text { or QTH. }
$$

The deposited flux $\left(\Phi_{\mathrm{i}}{ }^{\text {int }}\right)$ integrated over a HiPIMS period is defined as:

$$
\Phi_{\mathrm{i}}^{\mathrm{int}}=\int_{0}^{1 \mathrm{~ms}} \Phi_{\mathrm{i}}(\mathrm{t}) \mathrm{dt}
$$

This procedure was applied on TR-TDLIF measurements performed at two working pressures ( $\mathrm{p}=0.7$ and $2.7 \mathrm{~Pa}$ ), HiPIMS average power of $350 \mathrm{~W} . \mathrm{cm}^{-2}$ and as a function of the distance from the target " $\mathrm{z}$ " (figure 4).
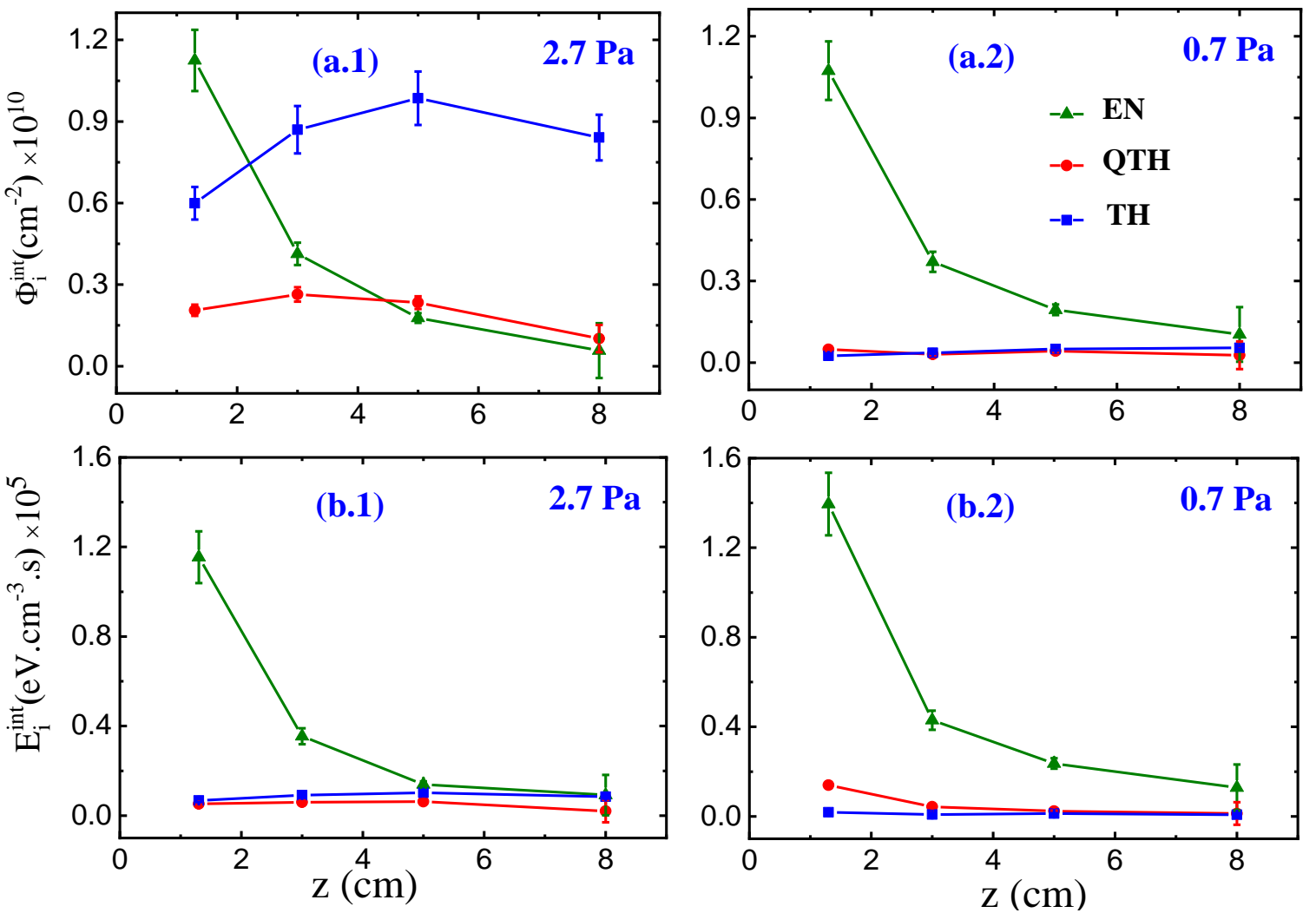

Figure 4: Axial evolutions of deposited fluxes $\left(\Phi_{E N}^{i n t}, \Phi_{Q T H}^{i n t}, \Phi_{T H}^{i n t}\right)(a .1$, a.2) and deposited energies $\left(E_{E N}^{i n t}, E_{Q T H}^{i n t}, E_{T H}^{i n t}\right)(b .1, b .2)$ at $p=2.7$ and $p=0.7 P a . R_{0}=1.3 \mathrm{~cm}, P=350 \mathrm{~W} . \mathrm{cm}^{-2}$, pure Ar.

At low pressure $(0.7 \mathrm{~Pa})$ the $\mathrm{EN}$ deposited flux and energy are dominant, even at $\mathrm{z}=8 \mathrm{~cm}$ (figures 4(a.2) and 4(b.2)). As expected, increasing the pressure up to $\mathrm{p}=2.7 \mathrm{~Pa}$, sputtered atoms undergoing more collisions, the $\mathrm{TH}$ atoms source term increases and their diffusive transport becomes slower (inducing fewer TH atoms losses during one post-discharge in the probed volume). Therefore, the main deposited flux depends on the distance from the target (figure 4(a.1)) and the TH one becomes dominant for $\mathrm{z}>2 \mathrm{~cm}$ in our conditions. However, due to their high energy, the EN deposited energy remains the highest up to $\mathrm{z} \sim 8 \mathrm{~cm}$ (figure 4(b.1)). In addition, $\Phi_{\mathrm{EN}}^{\mathrm{int}}(0.7 \mathrm{~Pa})$ and $\Phi_{\mathrm{EN}}^{\mathrm{int}}(2.7 \mathrm{~Pa})$ have the same behavior and nearly the 
same values (except for $\mathrm{z} \sim 8 \mathrm{~cm}$ ). It means that $\mathrm{EN}$ atoms flux depends little on the pressure in these ranges of parameters ( $p$ and $z \leq 5 \mathrm{~cm}$ ). In fact, for these typical HiPIMS process conditions, the effect of collisions seems then limited, i.e. only a few percent of EN atoms produced during "one" of HiPIMS discharges are thermalized. TH flux shown in figure 4(a.1) is probably the result of an accumulation of residual atoms on successive HiPIMS discharges.

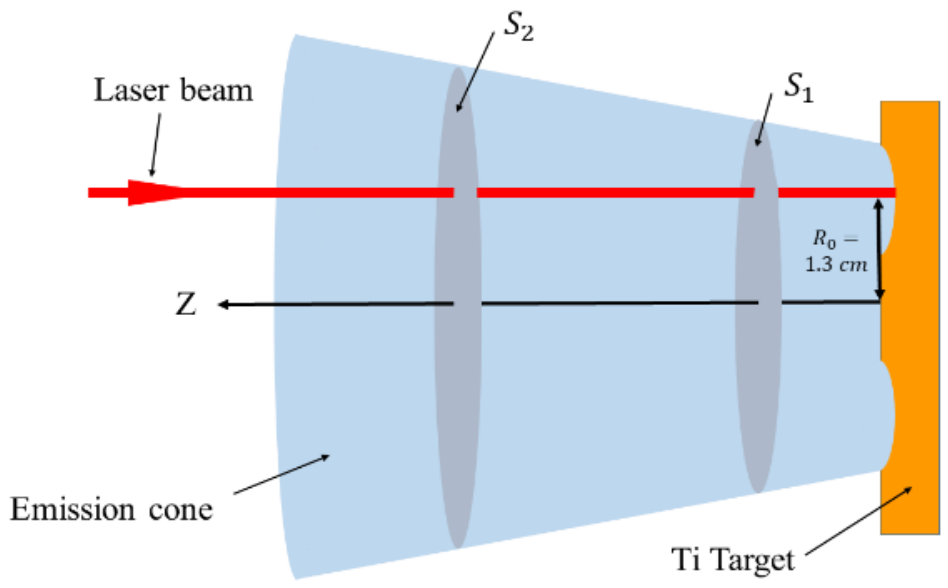

Figure 5: Scheme of the sputtered emission cone.

For both pressures, the $\Phi_{\mathrm{EN}}^{\mathrm{int}}(\mathrm{z})$ drop is mainly due to the emission cone of the sputtered atoms (figure 5). Indeed, EN atoms are ejected in a cosine emission ejected distribution [3] (see chapter 2, page 37), and consequently about $70 \%$ of the sputtered vapor is globally emitted in a $\theta=45^{\circ}$ emission cone with respect to the normal of the target surface. In order to illustrate this effect, we have assumed that the area of the emission cone section is given by $\mathrm{S}(\mathrm{z}) \approx \pi(\mathrm{z}+1.3)^{2}$.

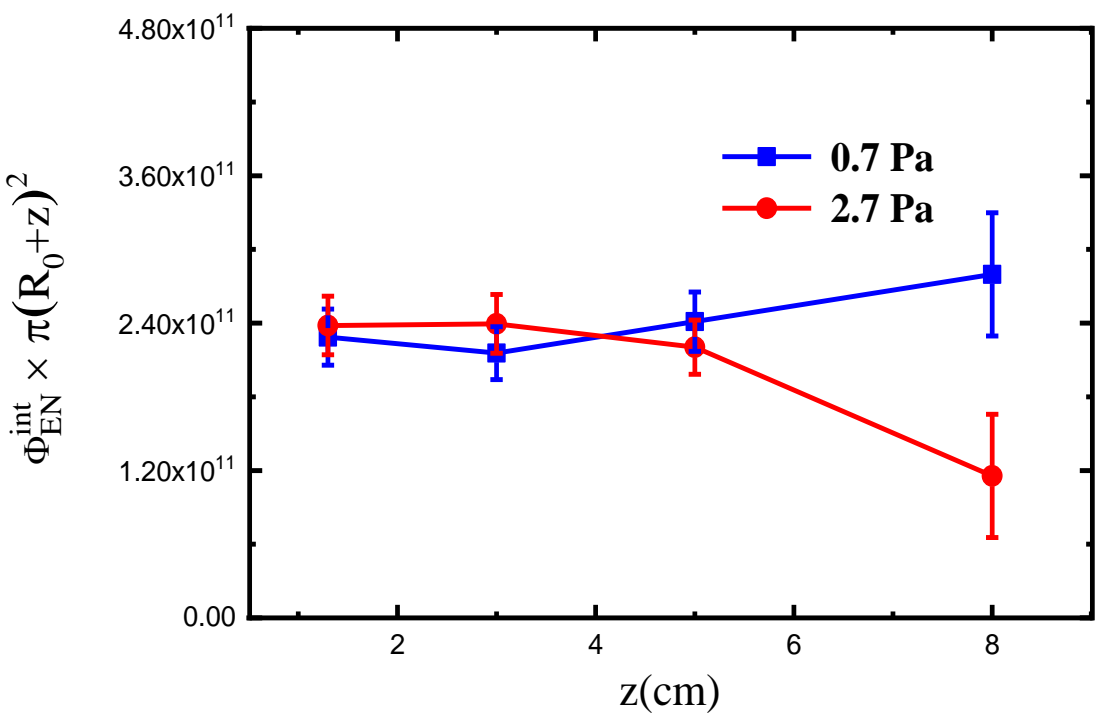

Figure 6: Corrected deposited fluxes : $\Phi_{E N}^{i n t} \times \pi(z+1.3)^{2}$. 
The corrected deposited fluxes taking into account the cone section, i.e. $\Phi_{\mathrm{EN}}^{\mathrm{int}} \times \mathrm{S}(\mathrm{z})$ are plotted in figure 6. At $\mathrm{p}=0.7 \mathrm{~Pa}$, the results show that the variations of the corrected deposited fluxes are very small. The slight discrepancy observed at $\mathrm{z}=8 \mathrm{~cm}$ is related to the weak measured TR-TDLIF signal and the uncertainties of the fit (traduced by greater error bars in the figure). Therefore, we can conclude that the losses of EN atoms during their transport towards the probed volumes are mainly due to the dispersion in the sputtering emission cone. At higher pressure $(2.7 \mathrm{~Pa})$, the real effect of collisions on EN atoms losses cannot be clearly distinguished in the range $0 \leq \mathrm{z} \leq 5 \mathrm{~cm}$.

\section{III-3. Characterization of the R-HiPIMS discharge $\left(\mathrm{Ar} / \mathrm{N}_{2}\right)$}

The above TR-TDLIF results give a comprehensive knowledge about the transport of the sputtered Ti neutral atoms in high power impulse magnetron sputtering without reactive gas. The scope of this section is to go further on the HiPIMS process studies by investigating the Ti atoms AVDF in Reactive(Ar/ $\mathrm{N}_{2}$ )-HiPIMS process (R-HiPIMS), at $\mathrm{p}=2.7 \mathrm{~Pa}$ while the discharge power is kept at $350 \mathrm{~W} . \mathrm{cm}^{-2}$.
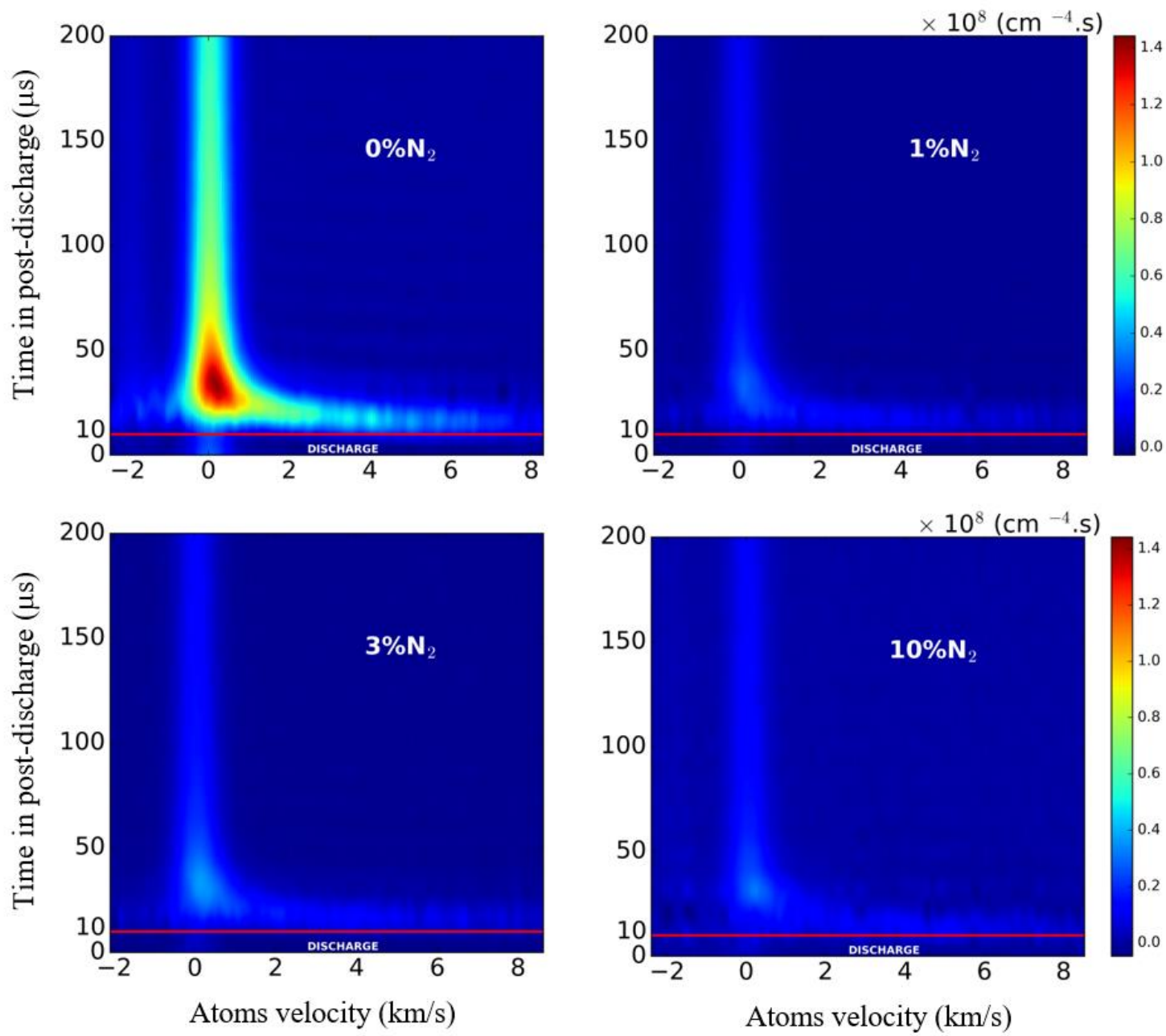

Figure 7: TR-TDLIF measurements of Ti neutral atoms velocity distribution functions for various Ar $/ N_{2}$ gas mixtures, at $p=2.7 P a, z=1.3 \mathrm{~cm}, R_{0}=1.3 \mathrm{~cm}$ and $P=350 \mathrm{~W} . \mathrm{cm}^{-2}$. 
It is well known that $\mathrm{N}_{2}$ and $\mathrm{N}$ species (neutrals and ions) react with deposited titanium atoms on the substrate forming titanium nitride $(\mathrm{TiN})$, and they also react with the reactor walls and the target surface. The latter process is called "poisoning of the target".
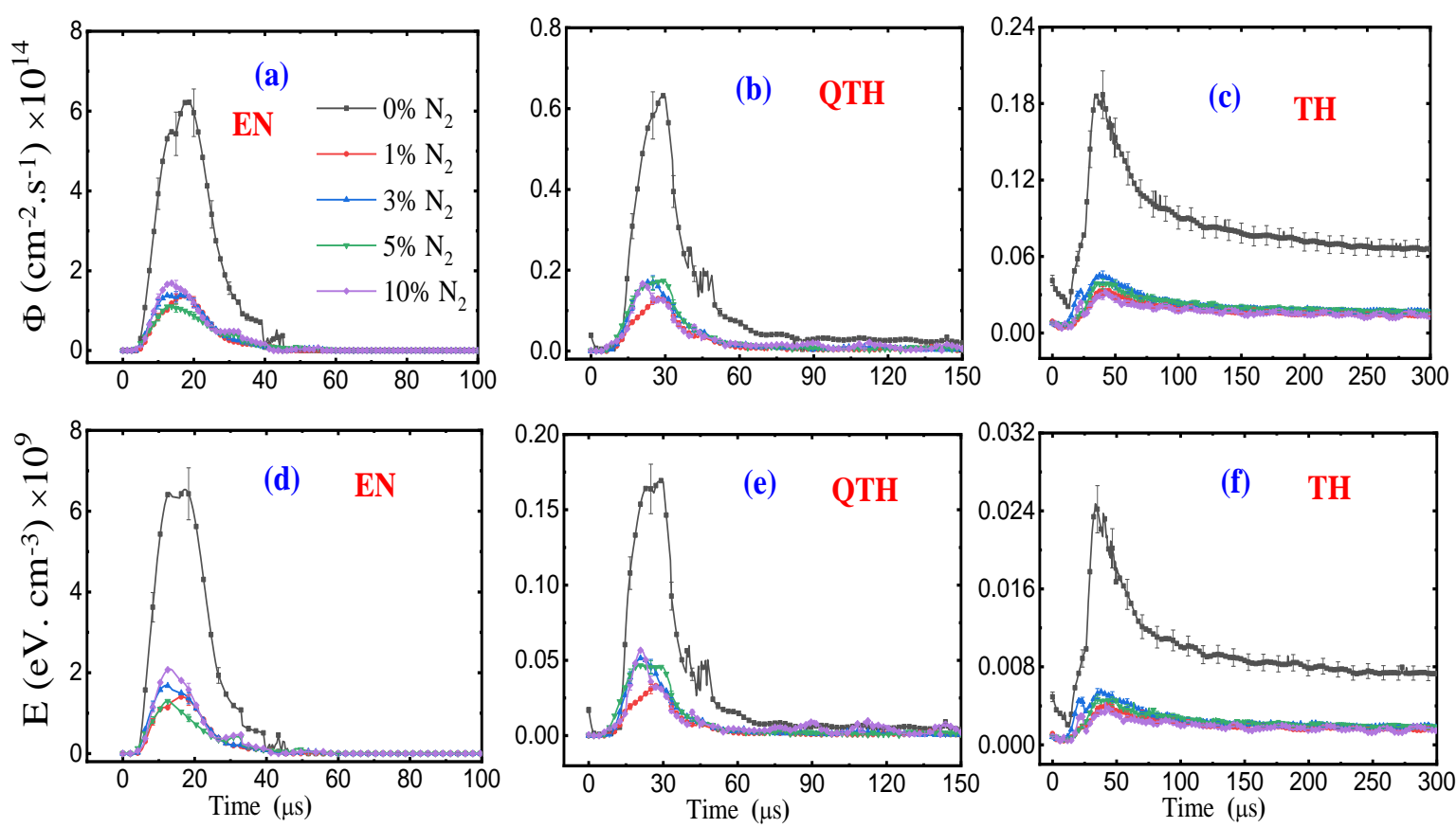

Figure 8: Temporal evolutions of deposited flux of energetic (a), quasi-thermalized (b) and thermalized (c) atoms as function of Ar/ $\mathrm{N}_{2}$ gas mixture. Time variations of deposited energy of energetic (d), quasi-thermalized (e) and thermalized ( $f$ ) atoms for various $A r / N_{2}$ gas mixtures. $P=350 W . \mathrm{cm}^{-2}, z=1.3 \mathrm{~cm}, R_{0}=1.3 \mathrm{~cm}, p=2.7 \mathrm{~Pa}$.

The $\mathrm{N}_{2}$ addition in the gas mixture $\left(\% \mathrm{~N}_{2}\right)$ induces changes of all process parameters, among them, the cathode voltage $\left(\mathrm{U}_{\text {cathode }}\right)$, electron density, yield of secondary electrons emitted from the cathode and the Ti sputtering yield. In our conditions $\left(0 \leq \% \mathrm{~N}_{2} \leq 10 \%\right.$ leading to $550 \leq \mathrm{U}_{\text {cathode }} \leq-450 \mathrm{~V}$ ), the yield of secondary electrons is slightly modified with the formation of TiN compound layer on the target [44]. In order to evaluate the $\% \mathrm{~N}_{2}$ influence on the sputtering yield, sputtered titanium neutral atoms AVDFs were measured for various gas mixtures near to magnetron target at $\mathrm{z}=1.3 \mathrm{~cm}$ (figure 7). One can see that in pure Ar the maximum of the $\operatorname{AVDF}(\mathrm{t})$ reaches $1.4 \times 10^{8}\left(\mathrm{~cm}^{-4}\right.$. s). Adding nitrogen, the distributions show that fewer sputtered atoms are detected (the maximum is about $0.3 \times 10^{8}\left(\mathrm{~cm}^{-4} . \mathrm{s}\right)$ ) whatever is the $\% \mathrm{~N}_{2}$. The poisoning seems to strongly occur on the target and much less $\mathrm{Ti}$ atoms are sputtered in our conditions. Indeed, the chemical (covalent) Ti-N compound bond strength is much stronger than the Ti-Ti metallic one (8.04 eV [45] and $6.6 \mathrm{eV}$, respectively). Figure 8 reports time variations of deposited flux and energy of EN, TH and QTH populations calculated from results of figure 7. They drastically decrease from $\% \mathrm{~N}_{2}=1 \%$ and no significant changes can be noticed on temporal evolutions up to $10 \%$.

The deposited flux $\left(\Phi_{\mathrm{i}}^{\mathrm{int}}\right)$ and energy $\left(\mathrm{E}_{\mathrm{i}}^{\mathrm{int}}\right)$ integrated over a HiPIMS period (using equations (5) and (6)) are plotted in figure 9 as a function of $\% \mathrm{~N}_{2}$ and for $\mathrm{z}=1.3,3$ and $5 \mathrm{~cm}$. It is worth 
noting that $\Phi_{\mathrm{Total}}^{\mathrm{int}}=\Phi_{\mathrm{EN}}^{\mathrm{int}}+\Phi_{\mathrm{QTH}}^{\mathrm{int}}+\Phi_{\mathrm{TH}}^{\mathrm{int}}$ and $\mathrm{E}_{\mathrm{Total}}^{\mathrm{int}}=\mathrm{E}_{\mathrm{EN}}^{\mathrm{int}}+\mathrm{E}_{\mathrm{QTH}}^{\mathrm{int}}+\mathrm{E}_{\mathrm{TH}}^{\mathrm{int}}$. According to figure $8(\mathrm{z}=1.3 \mathrm{~cm})$, the flux and energy directed toward the substrate (or the probed volume) of each population have the same $\% \mathrm{~N}_{2}$ dependency behavior up to $\mathrm{z}=5 \mathrm{~cm}$. This seems to confirm that the drastic decrease from $\% \mathrm{~N}_{2}=1 \%$ is mainly due to poisoning of the target and that the transport processes (collisions) of each population are not significantly influenced by the amount of nitrogen in the gas mixture (below $10 \%$ ). Furthermore, from figure 9 , we can deduce that, wathever is the $\% \mathrm{~N}_{2}$ (see figure 10), $\Phi_{\mathrm{EN}}^{\mathrm{int}}(\mathrm{z}=1.3 \mathrm{~cm}$ ) corresponds to $\sim 60 \%$ of the total flux $\Phi_{\text {Total }}^{\text {int }}, \Phi_{\mathrm{TH}}^{\mathrm{int}} \sim 30 \%$ and $\Phi_{\mathrm{QTH}}^{\mathrm{int}} \sim 10 \%$. At $\mathrm{z}=3 \mathrm{~cm}$, the proportion of EN flux drops to $25-30 \%$, the TH one becomes the highest (55-60\%) and the QTH one is more significant $(15 \%)$. Further away from the target $(\mathrm{z}=5 \mathrm{~cm}), \Phi_{\mathrm{TH}}^{\mathrm{int}}$ is clearly dominant $(70-75$ $\%)$ but, as mentioned above (description of figure 4), $\mathrm{E}_{\mathrm{EN}}^{\mathrm{int}}$ remains the highest (due to high $\langle\mathrm{v}\rangle)$.
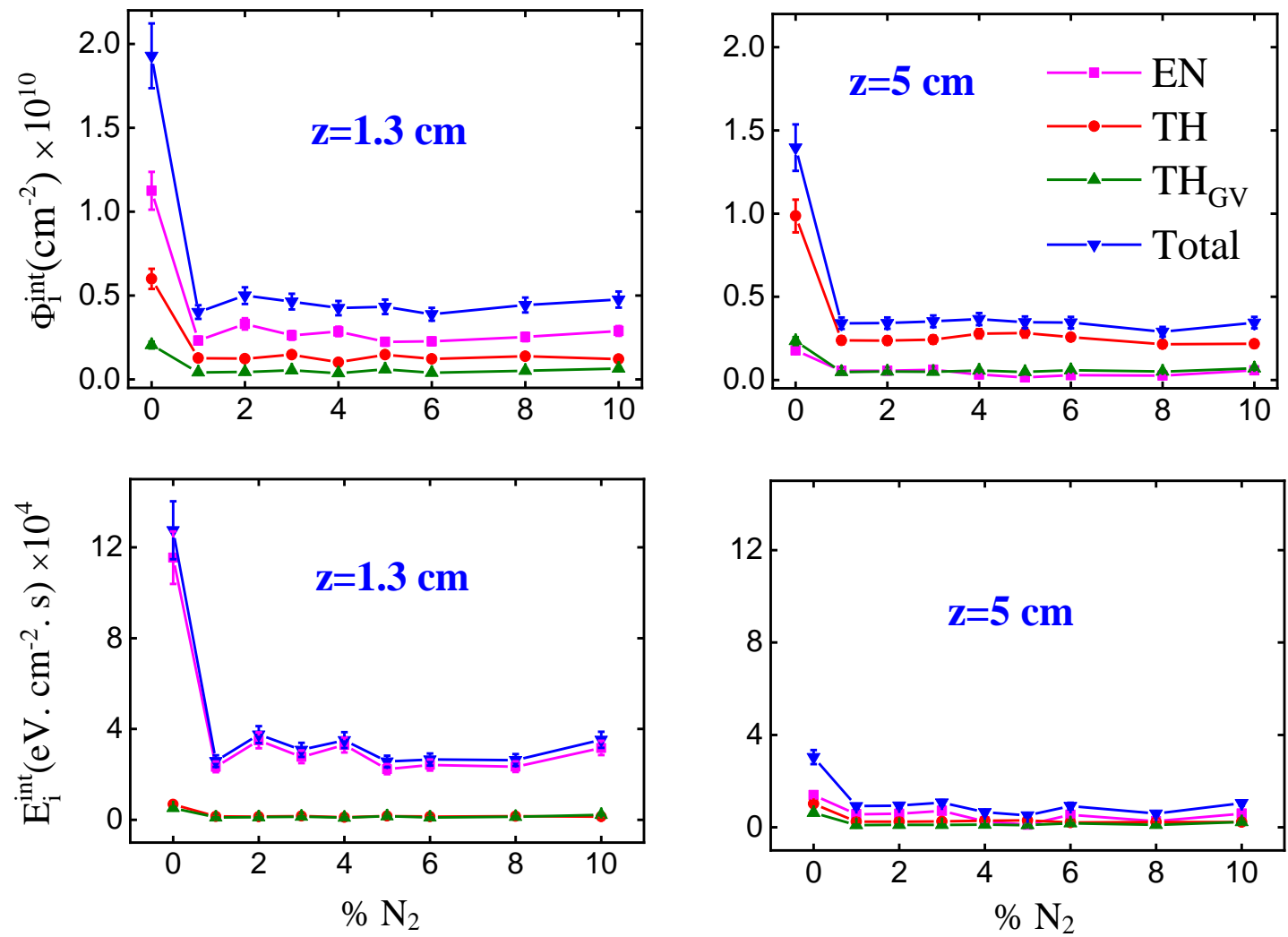

Figure 9: Variations of deposited fluxes $\left(\Phi_{E N}^{i n t}, \Phi_{Q T H}^{i n t}, \Phi_{T H}^{i n t}, \Phi_{\text {Total }}^{i n t}\right)$ as a function of $\% N_{2}$ (on the left side). Evolutions of corresponding deposited energies $\left(E_{E N}^{i n t}, E_{Q T H}^{i n t}, E_{T H}^{\text {int }}, E_{\text {Total }}^{\text {int }}\right)$ (on the right side). $z=1.3$ and $5 \mathrm{~cm}, P=350 \mathrm{~W} . \mathrm{cm}^{-2}, R_{0}=1.3 \mathrm{~cm}, p=2.7 \mathrm{~Pa}$.

These accurate measurements (time and space resolved) of energy and flux of neutral deposited species could be used to control and tune the properties of thin films (morphology, roughness, crystallinity, density or porosity, etc.) [46-48]. 

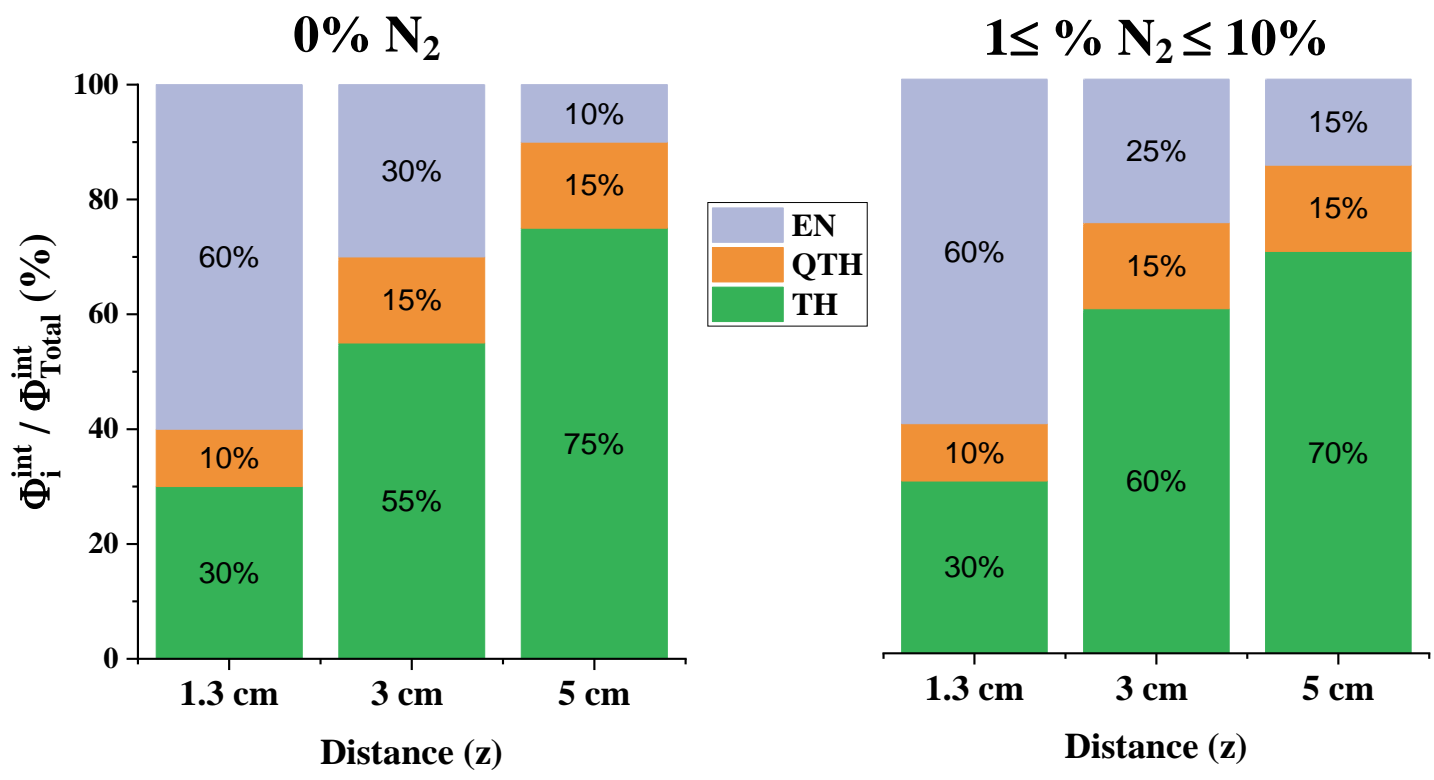

Figure 10: Fraction (\%) of the deposited flux of each population $\left(\Phi_{E N}^{i n t}, \Phi_{Q T H}^{i n t}, \Phi_{T H}^{i n t}\right)$ as a fonction 351 of the distance (z), at $\% \mathrm{~N}_{2}=0 \%$ (left side) and $1 \leq \% \mathrm{~N}_{2} \leq 10 \%$ (right side).

352 In order to verify if our $\Phi_{\text {Total }}^{\text {int }}$ measurements of Ti neutral atoms are well representative of all 353 deposited species (neutrals and ions), they were compared with the deposition rate measured 354 by means of SEM (scanning electron microscopy). Figure 11 shows that $\Phi_{\text {Total }}^{\text {int }}$ and the 355 deposition rate are in good agreement.

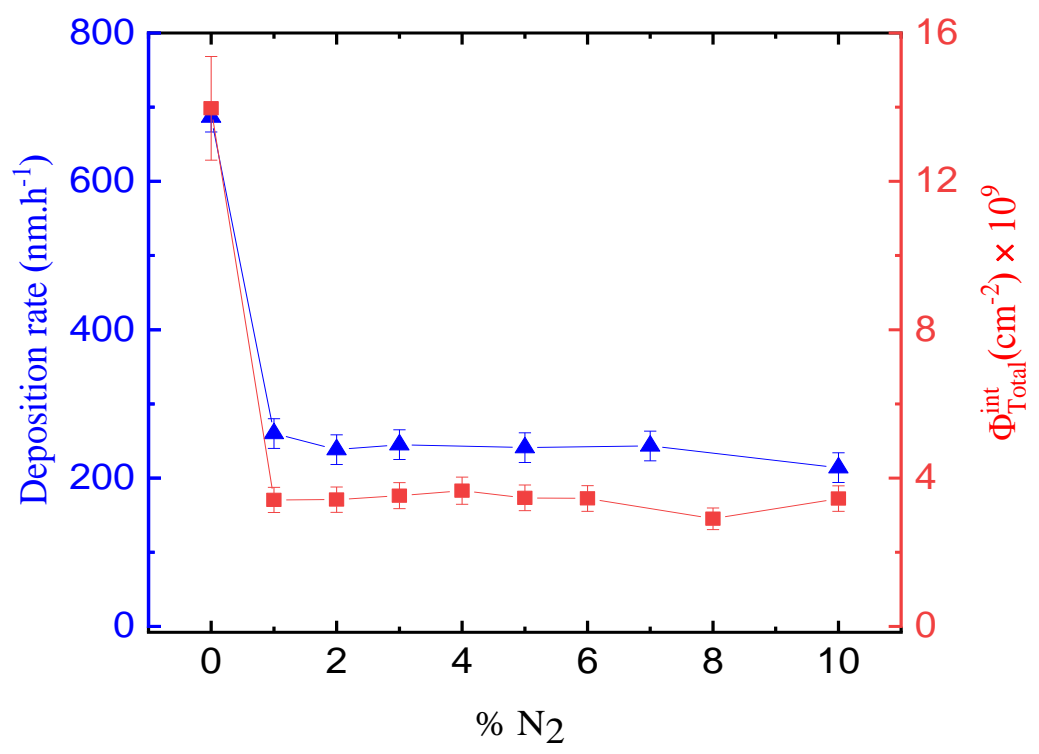

Figure 11: Variations of the total Ti neutral atoms deposited flux and the deposition rate at $z=5 \mathrm{~cm}$, 358 $P=350 \mathrm{~W} . \mathrm{cm}^{-2}, p=2.7 \mathrm{~Pa}, R_{0}=1.3 \mathrm{~cm}$, as a function of $\% \mathrm{~N}_{2}$. 
Nevertheless, the influence of $\% \mathrm{~N}_{2}$ on deposited flux of Ti neutral atoms in R-HiPIMS process was unexpected, i.e. we have expected a gradual decrease of $\Phi_{\text {Total }}^{\mathrm{int}}$ by adding nitrogen in gas mixture, as it is usually the case in conventional reactive direct current process (figure 12 points out this well-known phenomenon in our R-dcMS conditions)

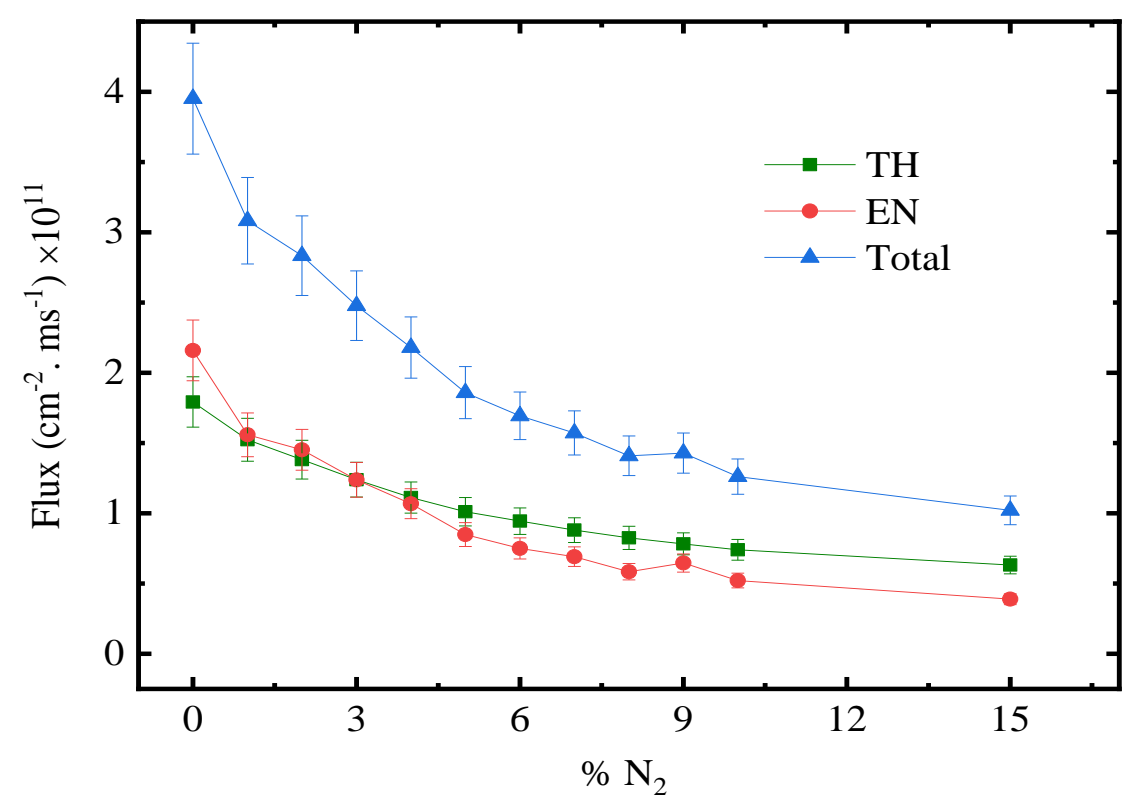

Figure 12:Variations of fluxes of Ti neutral atoms in DC discharge measured with TD-LIF, as a function of percentage of $N_{2}$, at $z=5 \mathrm{~cm}, p=1.3 \mathrm{~Pa}, P=5 \mathrm{~W} . \mathrm{cm}^{-2}$ and $R_{0}=1.3 \mathrm{~cm}$.

In HiPIMS process, the non-variation of $\Phi_{\text {Total }}^{\mathrm{int}}$ in the $\% \mathrm{~N}_{2}$ range from 1 to $10 \%$ may be implied by the gradual decrease of neutral $\mathrm{Ti}$ atoms ionization by adding nitrogen molecules in the argon gas. Indeed, the degree of ionization of the sputtered atoms may gradually decrease with increasing $\% \mathrm{~N}_{2}$, therefore the number of measured neutral atoms is higher than expected. To verify this possible assumption, $\mathrm{Ti}^{+}$time average ion energy distribution functions (TA-IEDF) were determined making use of mass spectrometry (Hiden EQP 300; Energy range between 0 and $100 \mathrm{eV}$ ). The total $\mathrm{Ti}^{+}$deposited flux was calculated integrating TA-IEDF with respect to energy (Figure 13). The variations, as a function of $\% \mathrm{~N}_{2}$, of $\mathrm{Ti}^{+}$flux and $\Phi_{\text {Total }}^{\text {int }}$ are alike. These very similar evolutions seem to prove that this unexpected behavior initially observed on $\Phi_{\text {Total }}^{\text {int }}$ cannot be explained by Ti ionization degree modification but is mainly due to the strong poisoning of the target from $\% \mathrm{~N}_{2}=1 \%$. We assume that in our HiPIMS conditions (at $\% \mathrm{~N}_{2}=1 \%$ ), the poisoning occurs during the relatively long post-discharge $(1 \mathrm{~ms})$ and the chosen short discharge time $(10 \mu \mathrm{s})$, the latter is not enough to remove the compound layer from the target in such a way as to be able to increase the poisoning process with $\% \mathrm{~N}_{2}>1 \%$. In R-dcMS process, the sputtering occurring continuously, the poisoning of the target is amplified with $\% \mathrm{~N}_{2}$. Furthermore, this behavior and the fact that the deposition rate is governed by the contribution of the neutrals may be probably due to the small power during the short HiPIMS pulse (small ionization degree of Ti atoms). 


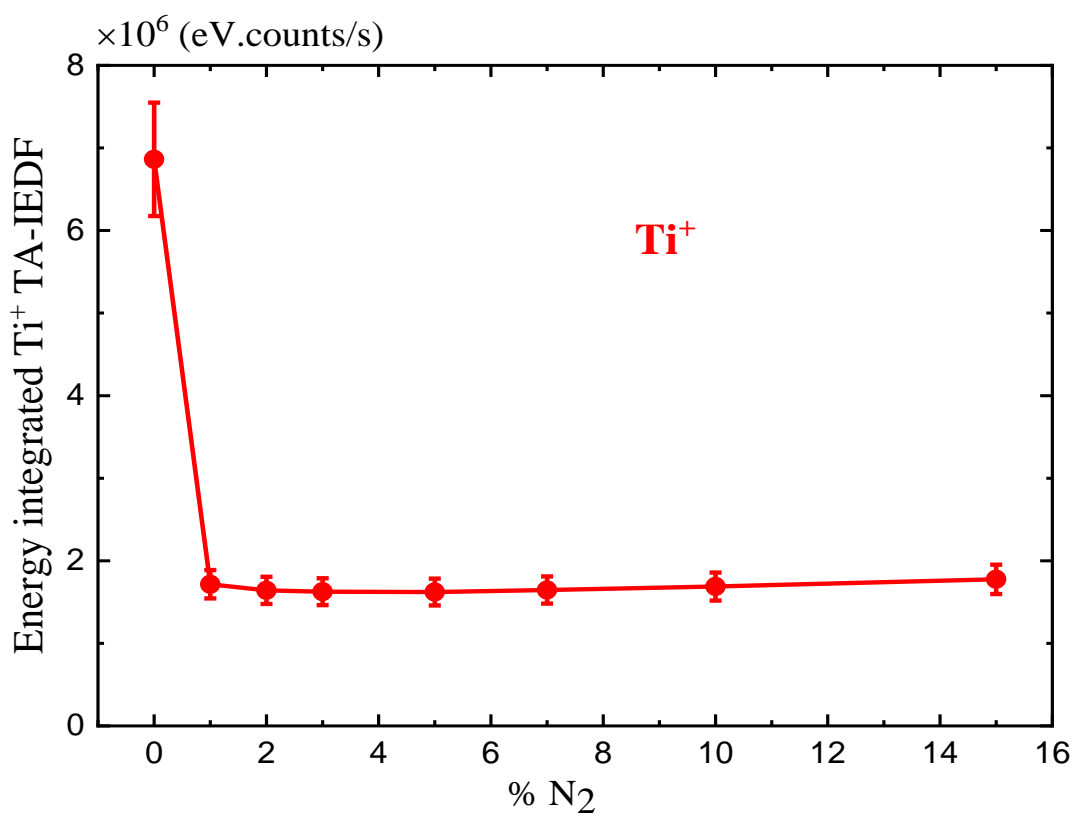

386

Figure 13: Variations of energy integrated $T i^{+}$TA-IEDF (time average-ion energy distrubution function) obtained by mass spectrometry, at $z=5 \mathrm{~cm}, p=2.7 \mathrm{~Pa}, P=350 \mathrm{~W} . \mathrm{cm}^{-2}, R_{0}=1.3 \mathrm{~cm}$, as a function of $\% \mathrm{~N}_{2}$.

\section{Conclusion}

This work was mainly focused on the characterization of sputtered titanium neutral atoms transport in reactive ( $\mathrm{Ar} / \mathrm{N}_{2}$ gas mixture) HiPIMS process. Time resolved tunable diode laser induced fluorescence (TR-TDLIF) measurements, originally developed to study the transport of tungsten atoms in non-reactive HiPIMS process [39], were performed to determine Ti atoms velocity distribution function (AVDF). From the analysis of the AVDF, three populations were detected and studied, i.e. the energetic (EN) sputtered atoms population (ballistic regime of transport), the thermalized (TH) atoms one (diffusive transport) and a third one was highlighted (named "QTH: Quasi Thermalized Atoms"). The latter corresponds to EN sputtered atoms which have undergone up to 5-6 collisions with the buffer gas, while 78 collisions are needed to reach a complete isotropic (axial mean velocity=zero) velocity distribution function. This means that this population of QTH atoms has a regime of transport close to the TH one but with an axial mean velocity directed towards the probed volume (or the substrate). Spatial studies, as a function of the distance from the target, indicate that the drop of EN atoms flux is mainly due to dispersion in the sputtering emission cone. The real effect of collisions on EN atoms losses is not clearly observed below $5 \mathrm{~cm}$ from the target, even at 2.7 Pa. Furthermore, it was shown that the transport processes (collisions with the buffer gas and $\mathrm{Ti}$ ionization degree), and consequently the flux fraction, of each population are not significantly influenced by the proportion of nitrogen in the gas mixture (up to $10 \%$ ). A direct comparison with the deposition rate allowed the consideration of the measurements on Ti neutral atoms as being well representative of the total deposited atoms (neutrals and ions). Thus, this direct characterization of deposited atoms properties being accessible at distance typically used in the industry $(5-10 \mathrm{~cm}$ from the target), TR-TDLIF measurements of 
deposited flux and energy can be exploited to tune thin film physical properties. Also such space-time experimental data may be useful for R-HiPIMS process modelling (as input data or benchmarks).

\section{References}

[1] Thornton, J. A. (1978). Journal of Vacuum Science and Technology, 15(2), 171-177.

[2] Mahieu, S., Ghekiere, P., De Winter, G., Heirwegh, S., Depla, D., De Gryse, R. \& Van Tendeloo, G. (2005). Journal of crystal growth, 279(1-2), 100-109.

[3] Powell, R. A. \& Rossnagel, S. (1999). PVD for Microelectronics: Sputter Deposition Applied to Semiconductor Manufacturing (Thin Films) Academic Press, London.

[4] Rossnagel, S. M., \& Hopwood, J. (1994). Journal of Vacuum Science \& Technology B: Microelectronics and Nanometer Structures Processing, Measurement, and Phenomena, 12(1), 449-453.

[5] Zhong, G., \& Hopwood, J. (1999). Journal of Vacuum Science \& Technology B: Microelectronics and Nanometer Structures Processing, Measurement, and Phenomena, 17(2), 405-409.

[6] Rossnagel, S. M. (1998). Journal of Vacuum Science \& Technology B: Microelectronics and Nanometer Structures Processing, Measurement, and Phenomena, 16(5), 2585-2608.

[7] Hopwood, J. (1998). Physics of Plasmas, 5(5), 1624-1631.

[8] Bretagne, J., Laporte, C. B., Gousset, G., Leroy, O., Minea, T. M., Pagnon, D., ... \& Touzeau, M. (2003). Plasma Sources Science and Technology, 12(4), S33.

[9] Zhang, J. Q., Setsuhara, Y., Ariyasu, T., \& Miyake, S. (1996). Journal of Vacuum Science \& Technology A: Vacuum, Surfaces, and Films, 14(4), 2163-2168.

[10] Yonesu, A., Kato, T., Takemoto, H., Nishimura, N., \& Yamashiro, Y. (1999). Japanese journal of applied physics, 38(7S), 4326.

[11] Boisse-Laporte, C., Leroy, O., De Poucques, L., Agius, B., Bretagne, J., Hugon, M. C., ... \& Touzeau, M. (2004). Surface and Coatings Technology, 179(2-3), 176-181.

[12] Nouvellon, C., Konstantinidis, S., Dauchot, J. P., Wautelet, M., Jouan, P. Y., Ricard, A., \& Hecq, M. (2002). Journal of applied physics, 92(1), 32-36.

[13] Yamashita, M., Setsuhara, Y., Miyake, S., Kumagai, M., Shoji, T., \& Musil, J. (1999). Japanese journal of applied physics, 38(7S), 4291. 
[14] Foster, J. E., Wang, W., Wendt, A. E., \& Booske, J. (1998). Journal of Vacuum Science \& Technology B: Microelectronics and Nanometer Structures Processing, Measurement, and Phenomena, 16(2), 532-535.

[15] Imbert, J. C., De Poucques, L., Boisse-Laporte, C., Bretagne, J., Hugon, M. C., Pagnon, D., ... \& Touzeau, M. (2008). Thin Solid Films, 516(15), 4700-4708.

[16] Kouznetsov, V., Macak, K., Schneider, J. M., Helmersson, U., \& Petrov, I. (1999). Surface and coatings technology, 122(2-3), 290-293.

[17] Anders, A. (2014). Surface and Coatings Technology, 257, 308-325.

[18] Gudmundsson, J. T., Alami, J., \& Helmersson, U. (2002). Surface and Coatings Technology, 161(2-3), 249-256.

[19] Bugaev, S. P., Podkovyrov, V. G., Oskomov, K. V., Smaykina, S. V., \& Sochugov, N. S. (2001). Thin Solid Films, 389(1-2), 16-26.

[20] Christie, D. J. (2005). Journal of Vacuum Science \& Technology A: Vacuum, Surfaces, and Films, 23(2), 330-335.

[21] Vlček, J., Pajdarová, A. D., \& Musil, J. (2004). Contributions to Plasma Physics, 44(56), 426-436.

[22] Alami, J., Gudmundsson, J. T., Bohlmark, J., Birch, J., \& Helmersson, U. (2005). Plasma Sources Science and Technology, 14(3), 525.

[23] Ehiasarian A P, Münz, W.-D. Hultman, L. and Helmersson, U. (April 13-18, 2002, Lake Buena Vista, Florida). 45th annual Technical Conference Proceedings (Society of Vacuum Coaters), 328 .

[24] Lattemann, M., Ehiasarian, A. P., Bohlmark, J., Persson, P. Å. O., \& Helmersson, U. (2006). Surface and Coatings Technology, 200(22-23), 6495-6499.

[25] Macák, K., Kouznetsov, V., Schneider, J., Helmersson, U., \& Petrov, I. (2000). Journal of Vacuum Science \& Technology A: Vacuum, Surfaces, and Films, 18(4), 1533-1537.

[26] Anders, A. (2017). Journal of Applied Physics, 121(17), 171101.

[27] Aiempanakit, M., Helmersson, U., Aijaz, A., Larsson, P., Magnusson, R., Jensen, J., \& Kubart, T. (2011). Surface and Coatings Technology, 205(20), 4828-4831.

[28] Ferrec, A., Kéraudy, J., \& Jouan, P. Y. (2016). Applied Surface Science, 390, 497-505.

[29] Ehiasarian, A. P., Vetushka, A., Hecimovic, A., \& Konstantinidis, S. (2008). Journal of Applied Physics, 104(8), 083305. 
[30] Palmucci, M., Britun, N., Silva, T., Snyders, R., \& Konstantinidis, S. (2013). Journal of Physics D: Applied Physics, 46(21), 215201.

[31] Greczynski, G., \& Hultman, L. (2010). Vacuum, 84(9), 1159-1170.

[32] Franz, R., Clavero, C., Kolbeck, J., \& Anders, A. (2016). Plasma Sources Science and Technology, 25(1), 015022.

[33] Britun, N., Minea, T., Konstantinidis, S., \& Snyders, R. (2014). Journal of Physics D: Applied Physics, 47(22), 224001.

[34] Vasina, P., Fekete, M., Hnilica, J., Klein, P., Dosoudilová, L., Dvorák, P., \& Navrátil, Z. (2015). Plasma Sources Science Technology, 24(6).

[35] Palmucci, M., Britun, N., Konstantinidis, S., \& Snyders, R. (2013). Journal of applied physics, 114(11), 113302.

[36] de Poucques, L., Imbert, J. C., Boisse-Laporte, C., Bretagne, J., Ganciu, M., Teulé-Gay, L., \& Touzeau, M. (2006). Plasma Sources Science and Technology, 15(4), 661.

[37] Held, J., Hecimovic, A., von Keudell, A., \& Schulz-von der Gathen, V. (2018). Plasma Sources Science and Technology, 27(10), 105012.

[38] Desecures, M., de Poucques, L., Easwarakhanthan, T., \& Bougdira, J. (2014). Applied Physics Letters, 105(18), 181120.

[39] Desecures, M., de Poucques, L., \& Bougdira, J. (2017). Plasma Sources Science and Technology, 26(2), 025003.

[40] Desecures, M., de Poucques, L., \& Bougdira, J. (2015). Plasma Sources Science and Technology, 24(1), 015012.

[41] Magnus, F., Sveinsson, O. B., Olafsson, S. \& Gudmundsson, J. T. (2011). Journal of Applied Physics, 110(8), 083306.

[42] Konstantinidis, S., Dauchot, J. P., Ganciu, M., Ricard, A., \& Hecq, M. (2006). Journal of applied physics, 99(1), 013307.

[43] Sushkov, V., Do, H. T., Cada, M., Hubicka, Z., \& Hippler, R. (2013). Plasma Sources Science and Technology, 22, 015002.

[44] Depla, D., Mahieu, S., \& De Gryse, R. (2009). Thin Solid Films, 517(9), 2825-2839.

[45] Du, L., Edgar, J. H., Kenik, E. A., \& Meyer, H. (2010). Journal of Materials Science: Materials in Electronics, 21(1), 78.

[46] Sarakinos K, Alami J and Konstantinidis S 2010. Surf. Coat. Technol. 204 1661-84. 
[47] Samuelsson M, Lundin D, Jensen J, Raadu M A, Gudmundsson J T and Helmersson U (2010). Surf. Coat. Technol. 205 591-6.

509 [48] Kersten H, Deutsch H, Steffen H, Kroesen G M W and Hippler R (2001) Vacuum 63 $510 \quad 385-431$. 